\title{
Steady-state creep in the mantle
}

\author{
G. Ranalli $(*)$
}

Received on October 25 th, 1977.

SUMmary - The creep equations for steady-state flow of olivine at high pressure and temperature are compared in an attempt to elucidate the rheological behaviour of the mantle. Results are presented in terms of applied deformation maps and curves of effective viscosity $v$ depth.

In the upper mantle, the transition stress between dislocation and diffusion creep is between $10^{-2}$ to $10^{2}$ bar (as orders of magnitude) lor grain sizes rom 0.01 to $1 \mathrm{~cm}$. The asthenosphere under continents is deeper, and has higher viscosity, than under oceans. Predominance of one creep mechanism above the others depends on grain size, strain rate, and volume fraction of melt; the rheological response can be different for different geodynamic processes.

In the lower mantle, on the other hand, dislocation creep is predominant at all realistic grain sizes and strain rates. If the effective viscosity has to be only slightly higher than in the upper mantle, as some interpretations of glacioisostatic rebound suggest, then the activation volume cannot be larger than $11 \mathrm{~cm}^{3} \mathrm{~mole}^{-1}$.

Rinssunto - Vengono confrontate le equazioni dello scorrimento plastico di olivina in equilibrio sotto condizioni di alta temperatura e pressionc, nel tentativo di spiegare il comportamento reologico del mantello. I risultati sono presentati sotto forma di mappe di deformazione applicata e di curve di effettiva viscosità. Nel mantello superiore, lo stress di transizione [ra dislocazione e diffusion creep è compreso tra $10^{-2}$ e $10^{2}$ bar (come ordine di grandezza) per grossezza della grana da 0.01 ad $1 \mathrm{~cm}$.

L'astenosfera è più profonda sotto $\mathrm{i}$ continenti ed ha viscosità più alta che sotto gli oceani. La preponderanza di un meccanismo di scorrimento sugli altri dipende dalla grossezza della grana, dalla velocità della deformazione e dalla parte di volume di fusione; la risposta reologica può essere diversa per diversi processi geodinamici.

(*) Department of Geology, Carleton University, Ottawa, Canada K1S 5B6́. 
Nel mantello inferiore, d'altra parte, lo scorrimento plastico di dislocazione è predominante rispetto a qualsiasi grossezza della grana e velocità di deformazione.

Se la viscosità effettiva deve essere solo leggermente più alta di quella nel mantello superiore, come alcune interpretazioni di "glacio-isostatic rebound» suggeriscono, allora il volume di attivazione non può essere più grande $\mathrm{di} 11 \mathrm{~cm}^{3}$ mole-1.

\section{INTRODUCTION.}

The problem of the rheology of the mantle over time scales of thousands of years or more still awaits solution. The most commonly used set of observations is provided by the isostatic rebound of areas formerly subjected to continental glaciation. Interpretation of these data has led to mant'e models exhibiting newtonian or maxwellian viscosity with a very pronunced low-viscosity zone (asthenosphere) in the upper mantle (cf. Walcott, 1975, for a review), or with very little variation of viscosity with depth (Peltier and Andrews, 1976). However, a mantle with non-newtonian viscosity increasing only slightly with depth at a given strain rate is also compatible with the evidence (Brennen, 1974). It appears therefore that, although models are being refined and their self-consistency improved, the analysis of the Earth's response to surface loading and unloading has not yet provided ways of discriminating among different models of mantle rheology.

An alternative approach consists in the direct determination of rheclogical properties by examination of upper mantle ultramafic rocks which have been transported to the surface by geodynamic processes. The textures observed in these rocks show that in most cases flow in the uppermost mantle is effected by dislocation motion and is therefore non-newtonian (Nicolas, 1976). Unfortunately, most specimens come from depths shallower than $100 \mathrm{~km}$, and consequently they provide no information on conditions prevailing below the lithosphere.

In response to these difficulties it seems reasonable to attempt determination of the rheological behaviour of the mantle by combining results on the experimental deformation of ultrabasic rocks at high pressure and temperature with theories of creep based on crystal physics. Studies adopting this type of approach (Weertman, 1970; Kirby and Raleigh, 1975; Ranalli, 1974) usually lead to the conclusion that the 
rheological behaviour of the mantle is non-newtonian with a power-law dependence of strain rate upon stress. In a very important paper, Stocker and Ashby (1973) have introduced the use of deformation maps for the mantle, and have produced applied deformation maps for an olivine upper mantle on the basis of experimental determinations of the rheological parameters of olivine and accounting in a semi-quantitative fashion for the influence of partial me!ting in the seismic low-velocity zone. This line of inquiry has been followed by TwIss (1976), who has proposed generalized grainboundary sliding as a possible mechanism to produce newtonian viscosity in the mantle, and by Ranalli (1977), who has constructed applied deformation maps for continental and oceanic upper mantle models by comparing the relative importance of dislocation creep, diffusion creep, superplastic creep and fluid phase transport at various pressures, temperatures and strain rates.

This paper presents and compares the rheological equations for the various modes of creep likely to occur in the mantle. Then, on the basis of recent determinations of the rheological parameters of olivine and of the defcrmation maps constructed by the author (1977), an attempt is made to determine the rheology of the mantle under various gcophysical conditions. Attention is focused on the upper mantle, since the rheological effects of the phase changes occurring in the transition zone are nct known; however, results for the lower mantle are also presented, on the understanding that they represent first approximations only.

EOUATIONS FOR CREEP IN POLYCRYSTALS.

The temperature conditions in the mantle of the Earth are such that steady-state creep is achieved over sufficiently long time intervals provided that the required stresses are present. At lower temperatures (less than abcut one-third of the melting temperature) the elastic component of the rheclogical behaviour is predominant, followed by a stage of transient creep during which the strain rate decreases with time. At temperatures pertaining to mantle conditions and sufficiently large strains, the transient creep is followed by steady-state creep during which the strain rate is constant under constant stress. Steadystate creep occurs when thermal annealing and recovery are sufficient 
to counter-balance work hardening caused by the multiplication of crystal defects brcught about by deformation; during steady-state creep, the defect structure of crystals is stochastically invariant.

The rheological equations (stress-strain rate relations) applicable to steady-state creep depend upon the mechanisms of flow and exhibit very good agreement with experimental results on polycrystals (metals, ceramics and rocks) at high pressure and temperature. In the sequel, only those equations that describe modes of creep of ultrabasic material (olivine polycrystals) at the stress levels relevant to the mantle, are included. (It is assumed that the creep strength is vanishingly small or in any case negligible when compared to stresses in the mantle). Discussion of creep mechanisms and of experimental results is kept to a minimum; more complete expositions can be found in the papers by Weertman (1970), Kirby and Raleigh (1973), and Stocker and Ashby (1973). The symbo's $\sigma$ and $\dot{\varepsilon}$ represent shear stress and shear strain rate, respectively.

\section{Nabarro-Herring creep.}

When creep is effected by diffusive fluxes of point defects (vacancies) across the crystal lattice and along grain boundaries, the rheological equation governing flow is

$$
\dot{\varepsilon}=\alpha \frac{D_{c} \mu \Omega}{k T d^{2}}\left(\frac{\sigma}{\mu}\right)
$$

where $\alpha$ is a numerical constant, $D_{C}$ the diffusion coefficient, $\mu$ the rigidity, $\Omega$ the atomic volume, $k$ Boltzmann constant, $T$ the absolute temperature, and $d$ the mean grain size. In the general case, the diffusion coefficient is the sum of two terms

$$
D_{C}=D_{V}+\frac{\pi \delta}{c^{l}} D_{B}
$$

where $D_{V}$ is the lattice diffusivity, $D_{B}$ the grain-boundary diffusivity, and $\delta$ is the grain-boundary width. The pressure and temperature dependence of the diffusivities is of the type

$$
D_{V}=D_{0} \exp \left(-\frac{E+P V}{R T}\right)
$$


where $D_{0}$ is a pre-exponential coefficient, $P$ the lithostatic pressure, $R$ the gas constant, and $E$ and $V$ are activation energy for self-diffusion and activaticn volume, respectively. (The $P, T$-dependence of $D_{B}$ is the same as that for $D_{V}$ but with a lower activation energy).

If $D_{V^{\prime}} \gg \frac{\pi \delta}{d} D_{R}$. flow is caused by the diffusion of vacancies through the lattice and the resulting creep is termed Nabarro-Herring creep, which is described by the equation

$$
\dot{\varepsilon}=\alpha \frac{D_{V} \mu \Omega}{k T d^{2}}\left(\frac{\sigma}{\mu}\right)
$$

It is of particular importance to note that in Nabarro-Herring creep the (newtonian) strain rate is inversely proportional to the square of the mean grain size.

Coble creep.

If $D_{V} \ll \frac{\pi \delta}{d} D_{B}$ the main agent of flow is the diffusion of vacancies along grain boundaries and the resulting creep is termed Coble creep; its rheological equation is

$$
\dot{\varepsilon}=\alpha \frac{D_{B} \pi \delta \mu \Omega}{k T d^{3}}\left(\frac{\sigma}{\mu}\right)
$$

with strain rate inversely proportional to the third power of grain size.

When the terms in the diffusion coefficient (equation [2]) are of comparab!e order of magnitude, both contribute significantly to creep; the boundary between Nabarro-Herring and Coble creep can be calculated by solving the equation

$$
D_{v}=\frac{\pi \delta}{d} D_{B}
$$

which yields ( $E^{\prime}$ being the activation energy for grain-boundary diffusion)

$$
T^{*}=-\frac{E-E^{\prime}}{R \ln \frac{\pi \delta}{d}}
$$


At the temperature $T^{*}$ given by [6] the contribution of the two mechanisms to the total creep is the same; for $T<T^{*}$ Coble creep is prediminant; for $T>T^{*}$ Nabarro-Herring creep is predominant. The boundary is pressure-independent but it depends on grain size: smaller grain sizes increase the transition temperature and therefore favour Coble creep.

Linear creep following equations [1], [4] or [5] is observed in very fine-grained ceramics at lcw stresses, but at higher stresses and grain sizes other mechanisms become predominant.

\section{Superplastic creep.}

Objections have been raised to steady-state creep of Nabarro-Herring and Coble type on the basis that, since the grain shape and size (and therefore the mean length of the diffusive paths) change during deformation, the strain rate under constant stress should be decreasing with time if no recrystallization or grain-bcundary migration occur. If, on the other hand, grains can freely slide past each other while remaining approximately equant, the mean length of the diffusion paths will not change during flow. Ashby and Verrall (1973) have proven that in this case, provided that grain boundaries can act as perfect sources and sinks of vacancies and have unhindered ability to slide, the creep law is identical to equation [1], but the strain rate is about seven times as fast, which can be taken care of by a suitable change in the numerical ccefficient $\alpha$. This type of diffusion-accomodated grain-boundary sliding is termed «superplastic » creep and is observed in metals at high temperature and large strains.

Superplastic creep can account for the behaviour of polycrystalline olivine in localized bands ("ductile faulting») at stresses of the order of kilobars, and on this basis it has been proposed that it may be a generalized mode of flow in the mantle (Twiss, 1976). However, such high stresses are hardly likely to be common throughout the mantle; furthermore, high confining pressure is liable to exert an inhibiting action on grain-boundary sliding. The possibility of superplastic creep being a widespread (as opposed to local) mode of flow in the mantle is therefore far from proven, and Nabarro-Herring and Coble creep, despite some inconsistencies, probability still represent the most realistic newtonian creep mechanisms in polycrystalline solids. 
Fluid phase transport.

The properties of the seismic low velocity zone are best explained by the presence of a small melt fraction in the ultrabasic upper mantle material (of Caloi, 1967, for a study of the crust and upper mantle, mainly at seismic frequencies). This molten phase is bound to affect, to a greater or lesser degree, the long-term rheological properties of the material. Stocker and Ashby (1973) have shown that flow in a polycrystal in the presence of a small amount of liquid coating the grains can be regarded as a generalization of linear creep (equation [1]), with an additional path of high diffusive conductance provided by the liquid phase. The diffusion coefficient in such a material will then be

$$
D_{C}^{*}=D_{V^{\prime}}+\frac{\pi \delta}{a^{*}} D_{B}+f c_{L} D_{L}
$$

where $f$ is the melt fraction, $c_{L}$ the solubility of the solid in the liquid, and $D_{L}$ the diffusivity in the liquid phase. The latter is related to the viscosity of the liquid $\eta_{L}$ by he equation

$$
D_{L}=\frac{k T}{8 \eta_{L} \Omega^{1 / 3}}
$$

Since diffusive transport through a liquid is generally faster than through a solid, under most conditions $f c_{L} D_{L} \gg D_{V}+\frac{\pi \delta}{d} D_{B}$ and therefore the rheological equation when fluid phase transport is predominant can be written as

$$
\dot{\varepsilon}=\alpha \frac{D_{L} \mu \Omega}{k T d^{2}} f c_{L}\left(\frac{\sigma}{\mu}\right)
$$

The evaluation of the importance of liuid phase transport as a flow mechanism in those parts of the upper mantle where partial melting occurs is complicated by the possibility of the presence of electroviscous effects in narrow fluid channels, which would greatly increase the viscosity of the melt. The apparent viscosity of a polar liquid in a channel less than about $10^{-4} \mathrm{~cm}$ in width is much larger than that of the bulk liquid, since the ordered structure at the liquid surface generates 
electrical gradients under shear which oppose the driving forces. The occurrence and magnitude of electroviscous effects in the low-velocity zone can only be guessed.

\section{Dislocation creep.}

In all the previous creep mechanisms plastic deformation of crystals is brought about by migration of point defects under non-hydrostatic stress: since the process is essentially one of vacancy diffusion (across the lattice, along grain boundaries, or using liquid paths) the term "diffusion creep » is applied collectively to them.

Plastic deformation can also be the result of the migration of line defects (dislccations) by glide, climb, crosslip and the like. Indeed, such « dislocation creep " is by far the most commonly observed mode of creep in naturally and experimentally deformed metals, minerals and rocks. In bcth cases, the rate-limiting processes is the diffusion of vacancies (to grain boundaries or to dislocations), and both diffusion and dislocation creep take place: the predominance of one upon the other depends on temperature, pressure, stress, grain size, and the properties of the material. The actual mechanism of the motion of dislocation is complex; however, if deformation is the result of a combination of climb and glide, the rheological equation takes the form

$$
\dot{\varepsilon}=\frac{3^{(n+1) / 2}}{2}-\frac{A D \mu b}{k T}\left(\frac{\sigma}{\mu}\right)^{n}
$$

where $A$ and $n$ are the Dorn parameters (independent of pressure and temperature), $b$ the Burgers vector, and the diffusion coefficient $D$ is identical to that for lattice diffusion [3]. Equation [10] has been experimentally verified for olivine single crystals and polyerystalline aggregates at stresses $\sigma / \mu \leq 10^{-3}$; at larger stresses it is no longer valid, and the dependence of strain rate upon stress becomes exponential. Its lower limit of validity is outside the stress levels commonly applied in experiments; however, movement and multiplication of dislocations should not occur at stresses $\sigma / \mu \leq 10^{-7}$ or $10^{-8}$. Long-term stresses in the bulk of the mantle are likely to be within these limits.

Two important characteristics of dislocation creep as compared to diffusion creep are grain-size independence and non-linearity (experimentally determined values of $n$ are usually comprised between 2.5 
and 4.5): hence the expression «power-law creep " to designate nonnewtonian flow with rheological equation [10]. The effective viscosity is therefore strain-rate dependent and this may strongly influence the determination of viscosity when the strain rate is not accurately known.

RHEOlogical PROPERTIES OF THE UPPER MANTLE.

The mantle above the transition zone is approximated as an olivine layer $\left(\sim F_{O_{90}}\right)$. The pressure and temperature variations with depth are shown in Fig. 1 for an oceanic and a continental upper mantle. The variation of rigidity with depth has been calculated using the equation

$$
\mu=\mu_{0}\left[1+\frac{1}{\mu_{2}} \frac{\partial \mu}{\partial T}\left(T-T_{0}\right)+\frac{1}{\mu_{0}} \frac{\partial \mu}{\partial !}\left(P-P_{0}\right)\right]
$$

with $\mu_{0}=0.79 \cdot 10^{12}$ dyn $\mathrm{cm}^{-2}$. The rigidity distribution calculated in this fashion shows some deviations from the distribution obtained from seismic data; however, given the uncertainties in the other parameters, these deviations should not be significant.

The values of the rheological parameters appearing in equations [1] to [10] which have been adopted in the computations are listed in Table 1. A discussion of these values has been offered elsewhere by the author (1977). Surveys of the state of the problem have been presented by Kirby and Raleigh (1973), Stocker and Ashby (1973), Carter (1976), and Twiss (1976).

A very useful and practical way of illustrating the rheology of the mantle under various geophysical conditions is afforded by deformation maps. The construction of such maps is a two-stage process (Stocker and Ashby, 1973): first, the fields in which a given creep mechanism is predominant are calculated in terms of $\sigma$ and $T$ at a given $P$; then, a geotherm is chosen and the fields are converted to be read directly against depth.

Field boundaries are defined as the $\sigma, P, T$-conditions at which two creep mechanisms contribute equally to the total strain rate, and they are obtained by solving pairs of rheological equation for $\sigma$. For instance, the boundary between dislocation and diffusion creep (without 


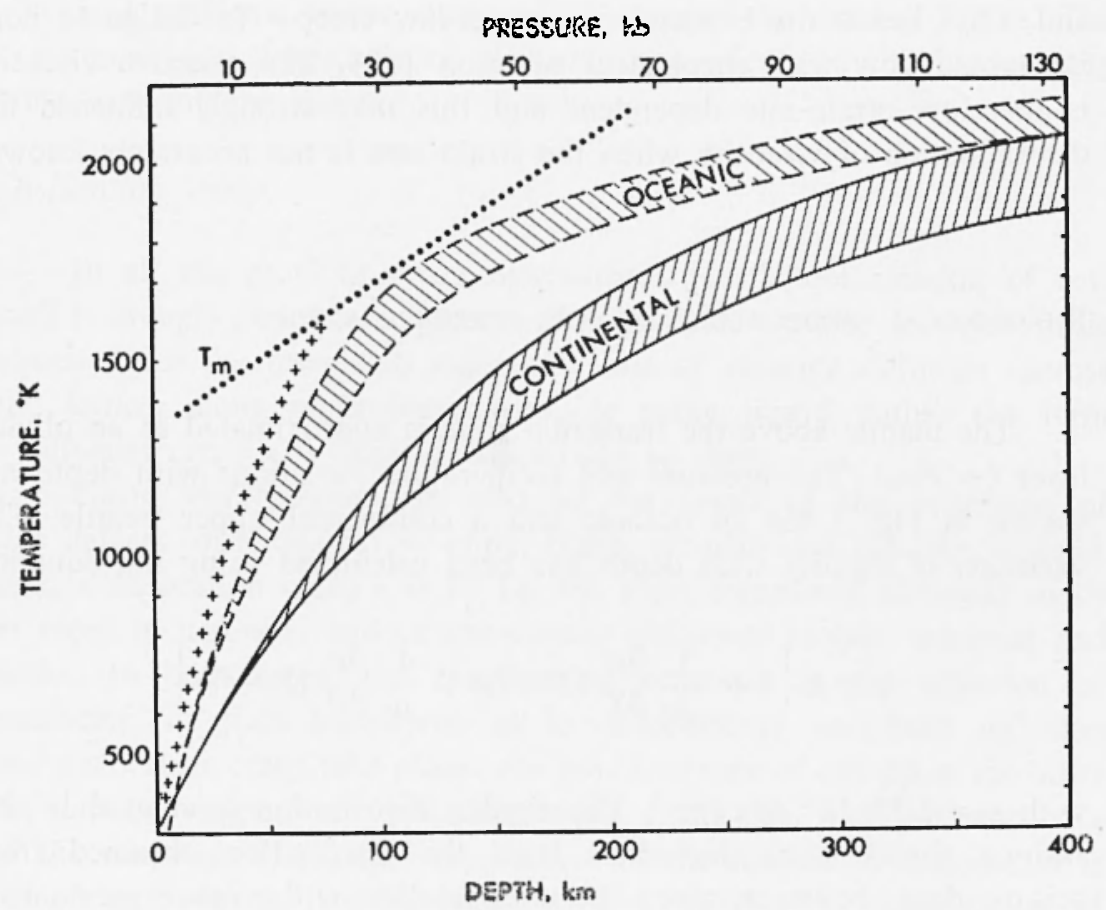

Fig. 1. Continental and oceanic geotherms in the upper mantle. Crosses represent the maximum temperature gradient in anomalous regions. Dotted line is the approximate solidus.

fluid phase transport) is given by

$$
\frac{\sigma}{\mu}-\left(\frac{2 \alpha}{9} \frac{D_{C} \Omega}{A D b d^{2}}\right)^{\frac{1}{2}}
$$

for $n=3$. At stresses larger than those given by [11], dislocation creep is predominant; at lower stresses, diffusion creep is. Within the diffusion field, Nabarro-Herring or Coble creep predominate according to temperature (equation [6]). If a liquid phase is present, $D_{C}$ in [11] should be substituted by $D_{c}^{*}$; the predominance of fluid phase transport over lattice and grain-boundary diffusion is established by comparing the three terms in equation [7] that make up the total diffusivity.

Curves of constant strain rate and constant viscosity can also be 
TABLE 1

\section{CREEP PARAMETERS FOR OLIVINE}

Numerical factor in diffusion crep . . . . . . . . $\alpha=2$ !

Dorn parameter . . . . . . . . . . . . . . $A=0.7$

Dorn parameter . . . . . . . . . . . . . . . . $n=3.0$

Burges vector . . . . . . . . . . . $b=6.98 \cdot 10^{-8} \mathrm{~cm}$

Atomic volume . . . . . . . . . . . . $\Omega=1.15 \cdot 10^{-23} \mathrm{~cm}^{3}$

Grain boundary width . . . . . . . . . . . . $\delta=1.4 \cdot 10^{-7} \mathrm{~cm}$

Grain size . . . . . . . . . . . . . $d=0.01-1 \mathrm{~cm}$

Pre-exponential diffusivity . . . . . . . . . . . $D_{0}=10^{3} \mathrm{~cm}^{2} \mathrm{sec}^{-1}$

Activation energy (latticc) . . . . . . . . . . $E=5.4 \cdot 10^{12}$ erg mole $\mathrm{m}^{-1}\left(\sim 130 \mathrm{kcal} \mathrm{mol}^{-1}\right)$

Activation energy (graim boundary) . . . . . . . . $E^{\prime}=3.6 \cdot 10^{12} \mathrm{erg}$ mole ${ }^{-1}\left(\simeq 87 \mathrm{kcal}^{\mathrm{mole}}{ }^{-1}\right)$

Activation volume . . . . . . . . . . . . $V=11 \mathrm{~cm}^{3} \mathrm{~mole}^{-1}$

Liquid phase fraction . . . . . . . . . . $f-0.001-0.01$

Solubility of solid in liquid ........... $C_{L} \simeq 10^{-\mathrm{i}}$

Liquid viscosity in the astenosphere ........ . . $\eta_{L} \simeq 10^{3}$ poise 
calculated and projected on the deformaion map. Except near field boundaries, one mechanism largely dominates over all others: therefore the stress associated with a given strain rate is obtained by solving the relevant rheological equation for $\sigma$ at a fixed $\dot{\varepsilon}$. The viscosity in diffusion creep is strain-rate independent and consequently can be directly calculated as a function of $P, T$ and $d$; in the dislocation field $(n=3)$, use is made of the relation

$$
\eta=\left(\frac{\sigma}{\mu}\right) \frac{\mu}{2 \varepsilon}=\frac{k T}{9 A D b\left(\frac{\sigma}{\mu}\right)^{2}}
$$

which yields

$$
\frac{\sigma}{\mu}=\left(\frac{k T}{9 A D b \eta}\right)^{\frac{1}{2}}
$$

solvable for $\sigma$ at a given viscosity.

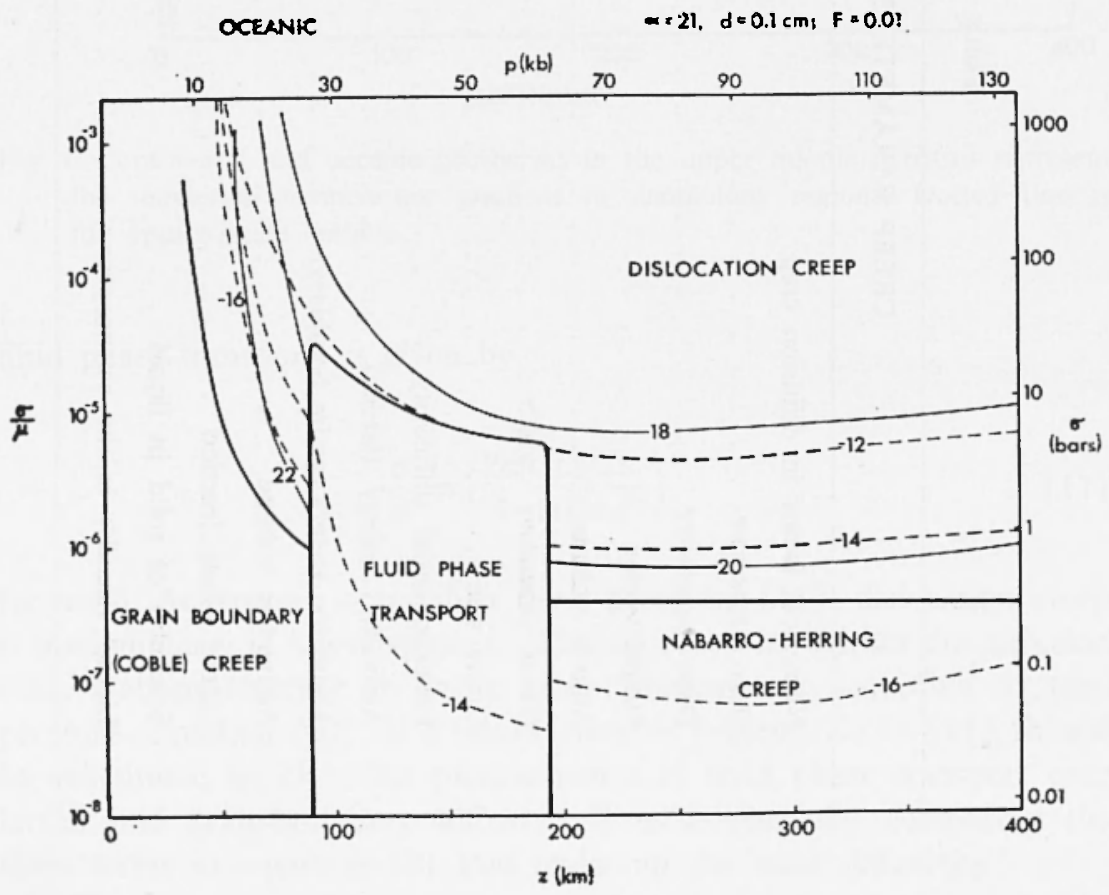

Fig. 2. Applied deformation map for oceanic upper mantle, grain size $0.1 \mathrm{~cm}$, liquid fraction in low-velocity zone $1 \%$. Thick continuous lines are field boundaries. Thin lines represent curves of constant viscosity in poise (given as powers of 10), and dashed lines curves of constant strain rates in $\sec ^{-1}$ (also as powers of 10 ). 
Some examples of applied deformation maps for oceanic and continental upper mantle are shown in Figs 2 to 5. From these and similar maps some statements can be made about the rheology of the upper mante. First of all, dislocation creep is predominant at high stresses, whereas at low stresses diffusion creep dominates. The transition stress is a function of temperature and grain size; with increasing $T$ the boundary becomes asymptotically horizontal, $D_{C}$ tends to $D$, and the transition stress depends only on grain size. The occurrence of partial melting increases the transition stress.

Fig. 6 shows the transition stress as a function of grain size at various temperatures; it varies from approximately 10 to 0.1 bar in the sublithospheric mantle without partial melting, and it is at most one order of magnitude larger in the presence of $1 \%$ melt. (This conclusion is valid if grain sizes in the upper mantle are of the same

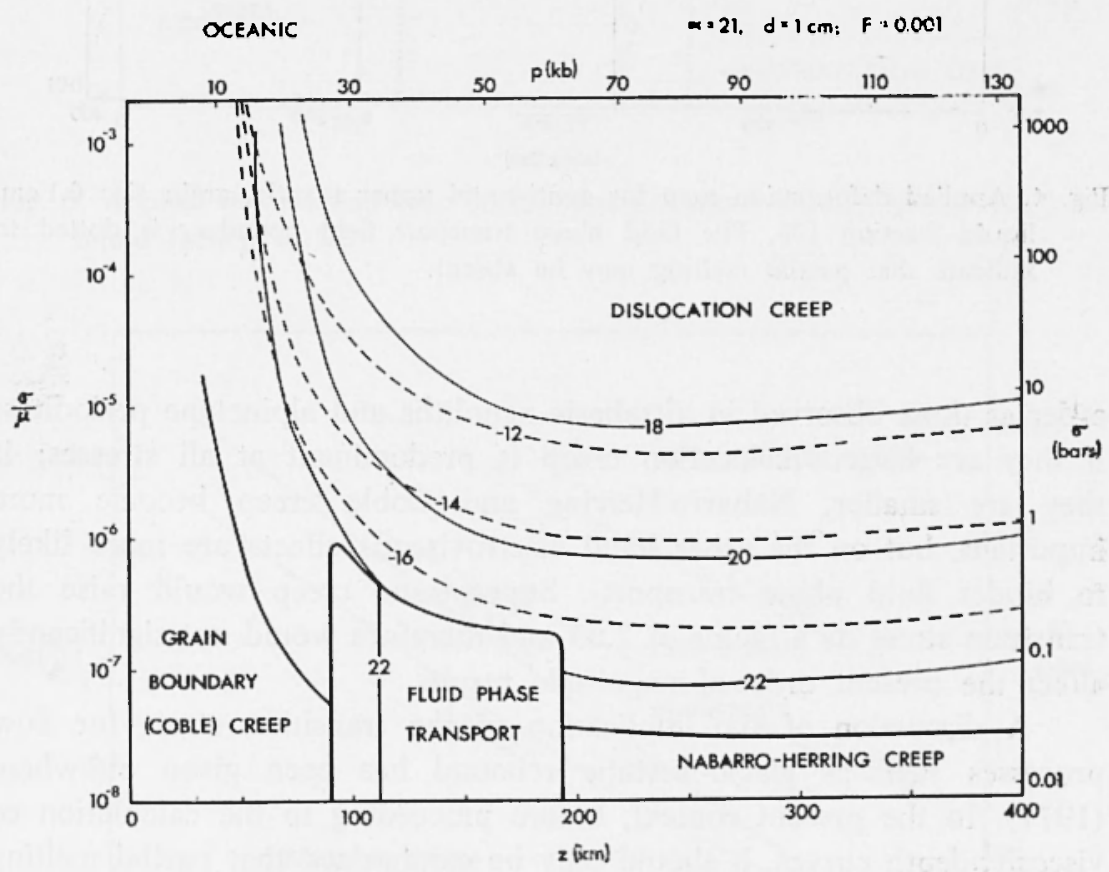

Fig. 3. Applied deformation map for oceanic upper mantle, grain size $1 \mathrm{~cm}$, liquid fraction $0.1 \%$. 


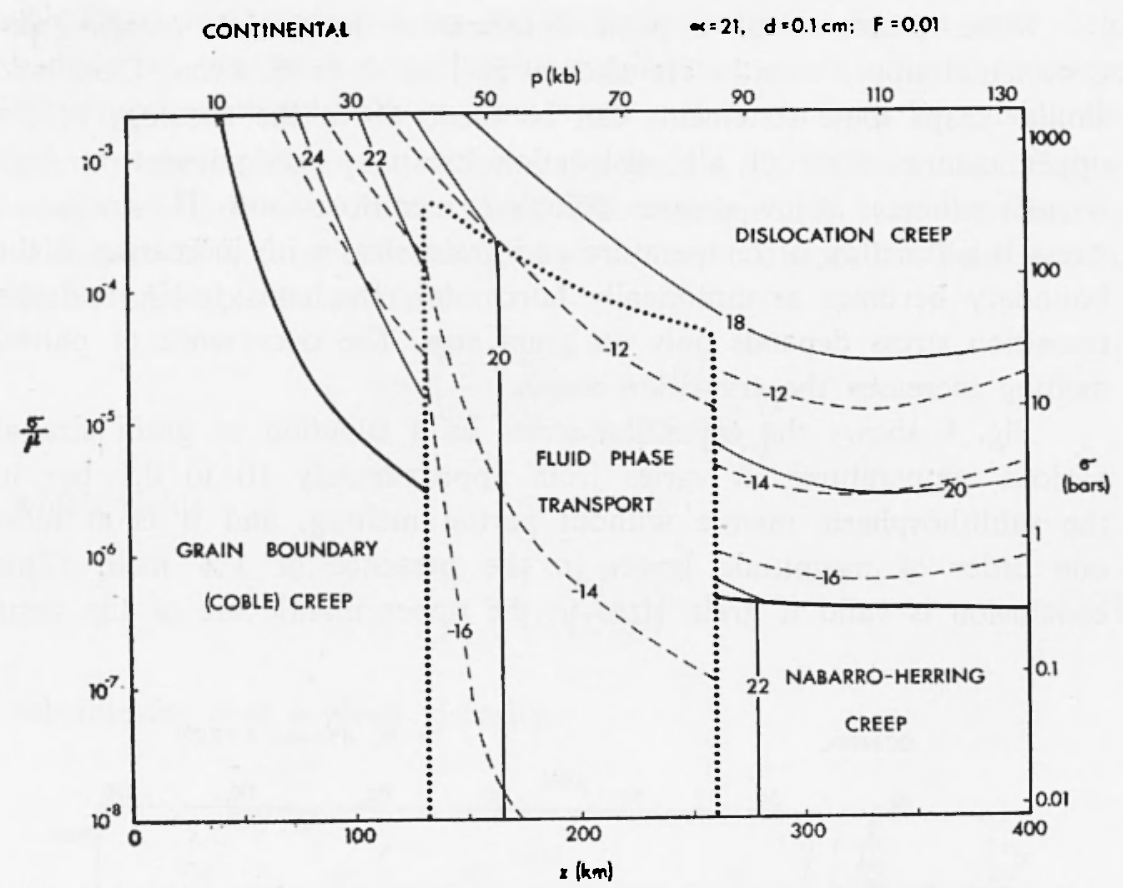

Fig. 4. Applied deformation map for continental upper mantle, grain size $0.1 \mathrm{~cm}$, liquid fraction $1 \%$. The fluid phase transport field boundary is dotted to indicate that partial melting may be absent.

order as those observed in ultrabasic xenoliths and alpinetype periodites; if they are larger, dislocation creep is predominant at all stresses; if they are smaller, Nabarro-Herring and Coble creep become more important, but on the other hand electroviscous effects are more likely to hinder fluid phase transport). Superplastic creep would raise the transition stress by a factor of 2.65 and therefore would not significantly affect the present order-of-magnitude results.

A discussion of the implication of the transition stress for flow processes such as glacio-isostatic rebound has been given elsewhere (1977). In the present context, before proceeding to the calculation of viscosity-depth curves, it should only be emphasized that partial melting affects the long-term rheological properties of the upper mantle only if the stresses are sufficiently small; at high stresses and high strain rates it has no effect. Therefore the "asthenosphere » (in the sense of low- 


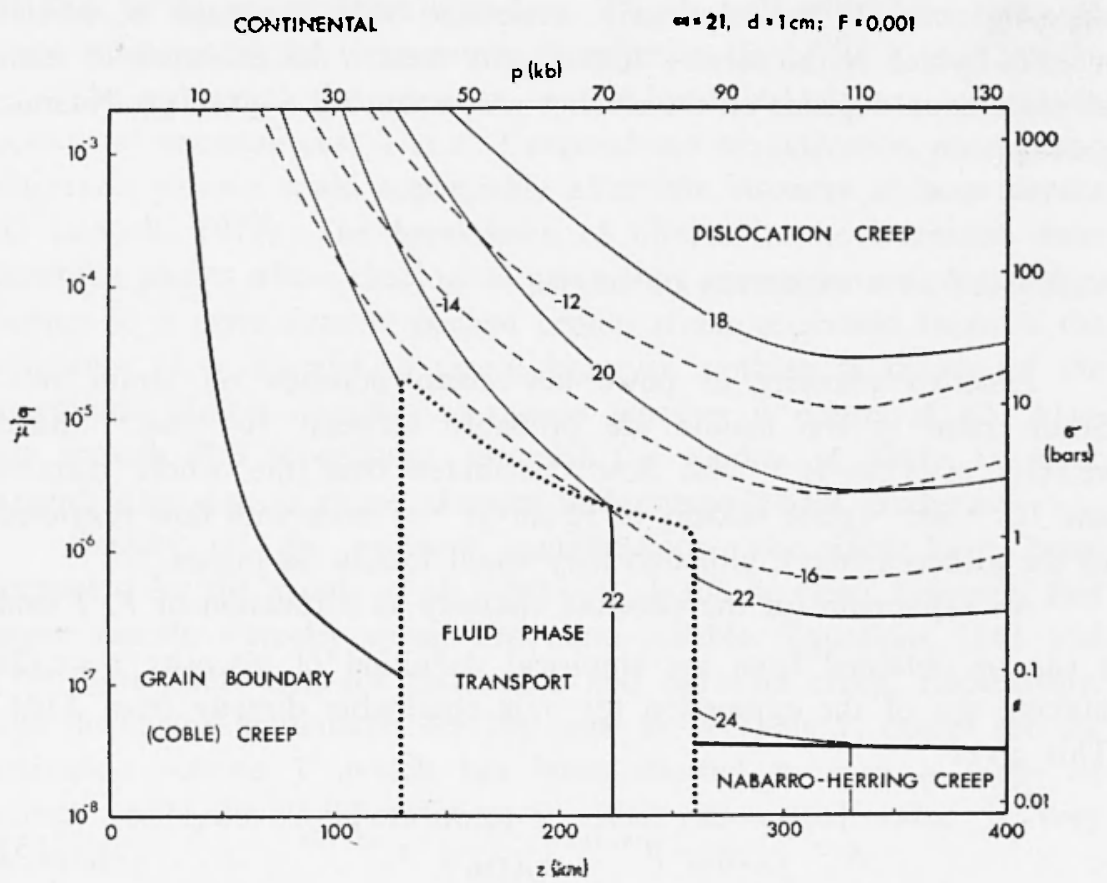

Fig. 5. Applied deformation map for continental upper mantle, graim size $1 \mathrm{~cm}$, liquid faction $0.1 \%$.

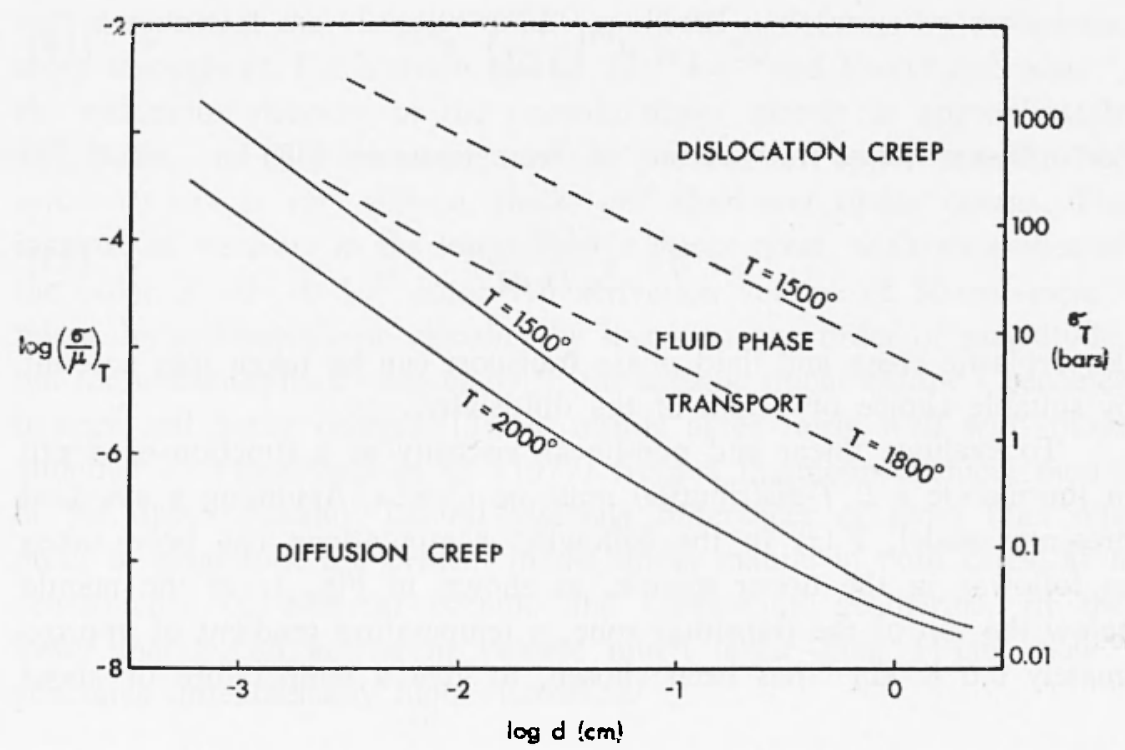

Fig. 6. Transition stress as a function of grain size at various temperatures. Continuous line: no partial melting. Dashed line: $1 \%$ melt. 
viscosity zone) is not necessarily associated with the zone of partial melting (which is the seismic low-velocity zone): the existence of such an association depends on the stresses accompanying a given geodynamic process.

VISCOSITY AS A FUNCTION OF DEPTH.

Effective viscosity in power-law creep depends on strain rate. Strain rates in the mantle are probably between $10^{-16} \cdot \mathrm{sec}^{-1}$ (plate ve'ocity of $1 \mathrm{~cm} \cdot \mathrm{yr}^{-1}$ with flow distributed over the whole mantle) and $10^{-13} \cdot \mathrm{sec}^{-1}$ (plate velocity of $10 \mathrm{~cm} \cdot \mathrm{yr}^{-1}$ or more with flow restricted to the asthencsphere), although they could locally be higher.

An expression for the effective viscosity as a function of $P, T$ and $\varepsilon$ can be obtained from the empirical definition of viscosity $\eta=\sigma / 2 \varepsilon$ making use of the expression for $\sigma / \mu$ obtainable directly from [10]. This gives

$$
\eta=\frac{2^{-(n-1) / n}}{3^{(n+1) / 2 n}} \mu^{(n-1) / n}\left(\frac{\dot{R} T}{A D b}\right)^{1 / n} \varepsilon^{-(n-1) / n}
$$

which becomes, for $n=3$,

$$
\eta=\frac{2^{-2 / 3}}{3^{2 / 3}} \mu^{2 \cdot 5}\left(\frac{k T}{A D b}\right)^{1 / 3} \varepsilon^{-2 / 3}
$$

For diffusion creep, the viscosity is (from equation [1])

$$
\eta=\frac{k T d^{2}}{2 \alpha D_{c} \Omega}
$$

(Superplastic creep and lluid phase transport can be taken into account by suitable choice of $\alpha$ and of the diffusivity).

To evaluate linear and non-linear viscosity as a function of depth in the mantle a $P, T$-distribution must be chosen. Assuming a standard pressure model, $T(z)$ in the following computations has been taken as follcws: in the upper mantle, as shown in Fig. 1; in the mantle below the top of the transition zone, a temperature gradient of approximately $0.6^{0} \mathrm{~K} \cdot \mathrm{km}^{-1}$ has been chosen, to give a temperature of about 
$3400^{\circ} \mathrm{K}$ at the mantle/core boundary. This is well within the limits of most estimates of the temperature distribution (Bott, 1971, p. 128).

The values of the viscosity in the lower mantle are subject to additional uncertainties. The $P, T$-dependence of activation energy and activation volume could appreciably affect the viscosity at large depths (O'Connell. 1977). The breakdown of olivine in the transition zone generates phases whose rheological parameters are not known. A transformation to a more densely packed crystal structure should increase the resistance of a material to creep; however, nothing is known of the magnitude of this increase, or indeed whether it occurs at all. Also, the smooth $P, T$-dependence assumed for rigidity is likely to mask irregularities due to phase changes and compositional gradients.

Despite all the provious qualifications, viscosities have been computed for the mantle at all depths; it should be clear, however, that upper mantle viscosity values are more reliable. Equations [14] and [15] have been used for dislocation and diffusion creep, respectively. The rheological parameters are the same as in Table 1, except for the activation volume $V$ which has been allowed to span a range of values $\left(6,11,20,30,50 \mathrm{~cm}^{3} \cdot \mathrm{mole}^{-1}\right)$, since its actual value is very uncertain.

The variation of effective viscosity with depth at three constant strain rates are shown in Figs. 7 and $\delta$ for continental and oceanic mant'e and $V=11 \mathrm{~cm}^{3} \cdot \mathrm{mole}^{-1}$ and $30 \mathrm{~cm}^{3} \cdot \mathrm{mole}^{-1}$, respectively. The curves represent the viscosity of the mantle if it deforms by dislocation creep throughout. For a strain rate of $10^{-14} \mathrm{sec}^{-1}$ and $V=11 \mathrm{~cm}^{3} \cdot \mathrm{mole}^{-}$, the minimum viscosity in the oceanic upper mantle is approximately $10^{20}$ poise, and slightly greater in the continental upper mantle. The asthenosphere is very diffuse, thick, and shallower under oceans. The increase of viscosity in the lower mantle is not great, with viscosities of the order of $10^{21}$ to $10^{23}$ poise. An activation volume of $30 \mathrm{~cm}^{3} \cdot \mathrm{mole}^{-1}$ raises the asthenospheric viscosity by less than one order of magnitude, but the asthenosphere - especially in the oceanic upper mantle - becomes thinner and better defined. (These results agree fairly well with those obtained by Froidevaux et al. (1977) from a thermo-mechanical model of the upper mantle). Lateral viscosity differences of more than one order of magnitude are present in the upper mantle in both cases, as a consequence of different oceanic and continental geotherms. In the lower mantle, an activation volume much larger than $11 \mathrm{~cm}^{3} \cdot \mathrm{mole}^{-1}$ generates unrealistically high viscosities. 


$$
V=11 \mathrm{~cm}^{3} \mathrm{~mole}^{-1}
$$

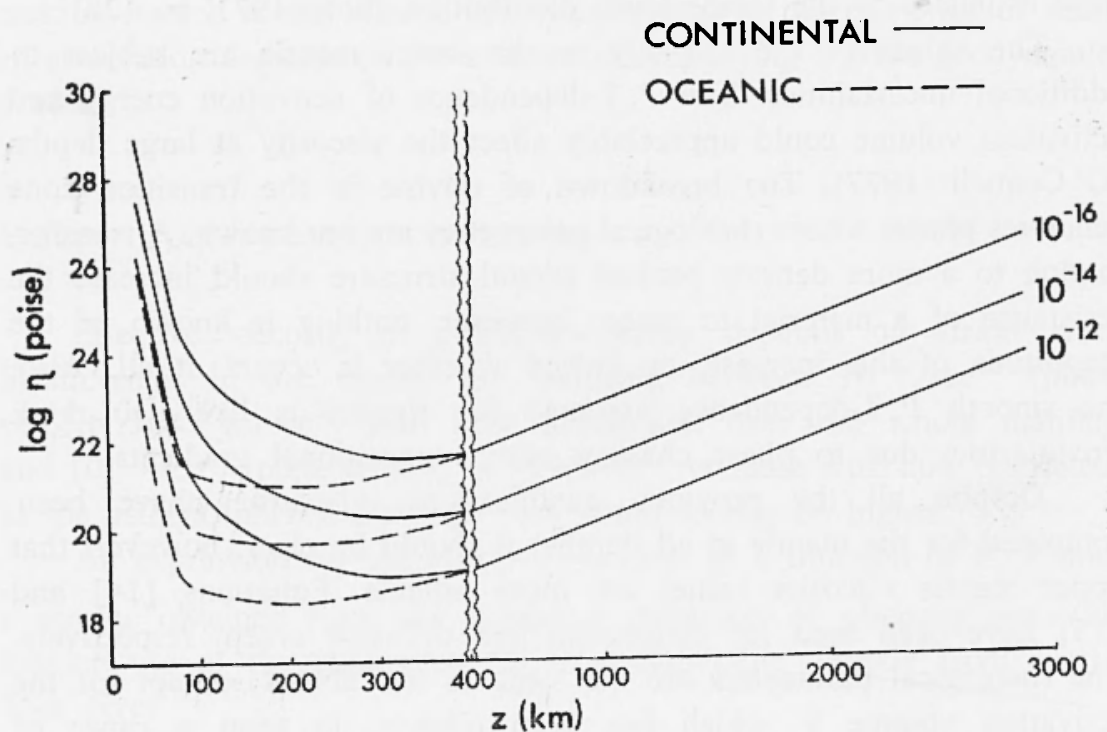

Fig. 7. Effective viscosity $v$. depth for dislocation creep, activation volume $11 \mathrm{~cm}^{3}$ mole $-i$. at three given strain rates. Change of depth scale at $400 \mathrm{~km}$. No lateral differences in mantle properties are assumed to exist below this depth.

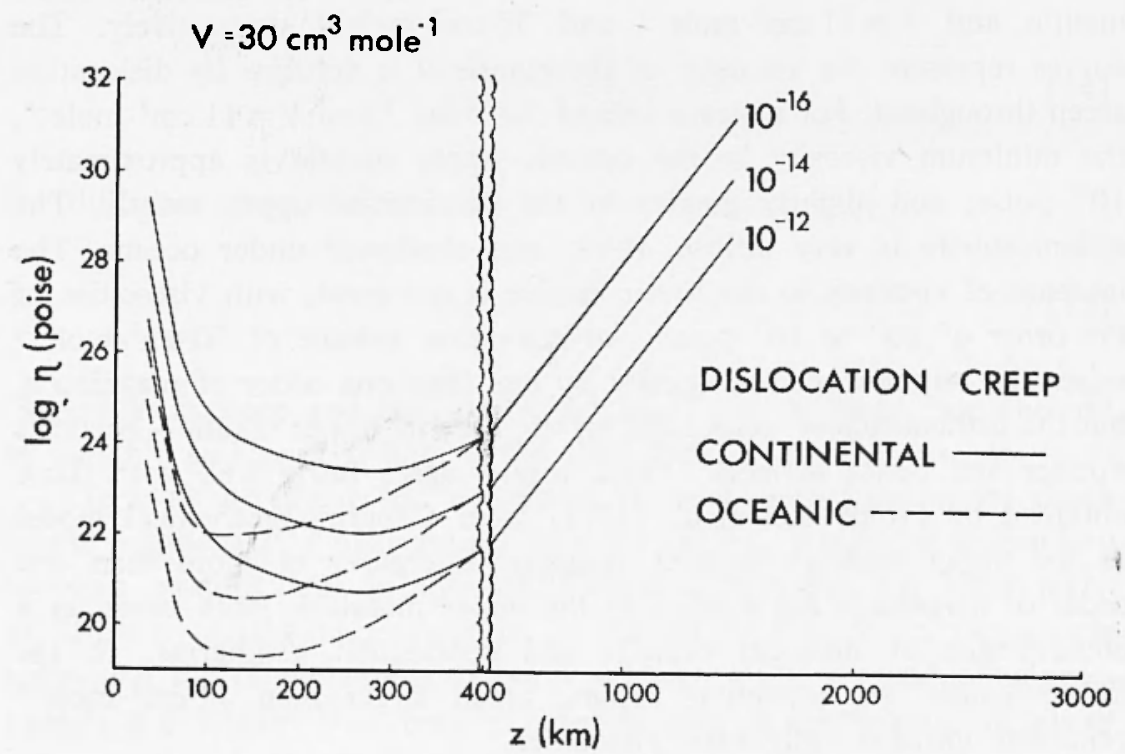

Fig. 8. Effective viscosity $v$. depth for dislocation creep, activation voluitue $30 \mathrm{~cm}^{3} \mathrm{~mole}^{-1}$. 
Viscosity as a function of depth in diffusion creep (Nabarro-Herring and Coble) is given in Figs 9 and 10 for the same values of the activation volume. For the case $V=11 \mathrm{~cm}^{3} \cdot \mathrm{mole}^{-1}$, two curves, one for $d=0.1 \mathrm{~cm}$ and the other for $d=0.01 \mathrm{~cm}$, are given. For $V=30 \mathrm{~cm}^{3} \cdot \mathrm{mole}^{-1}$, only the case $d=0.01 \mathrm{~cm}$ is presented, this being the most favourable case for diffusion creep. Lower mantle viscosities are very high for all activation volumes; in the upper mantle, however, lcw activation volume and small grain size make diffusion creep competitive with respect to dislocation creep. The asthenosphere shows horizontal and vertical variations that are qualitatively similar to those pertaining to dislocation creep.

A direct comparison of diffusion and dislocation creep viscosities allows the determination of the predominant deformation mechanism at any given depth: the mechanism associated with the lower viscosity generates the larger strain rate and therefore dominates. Since viscosity

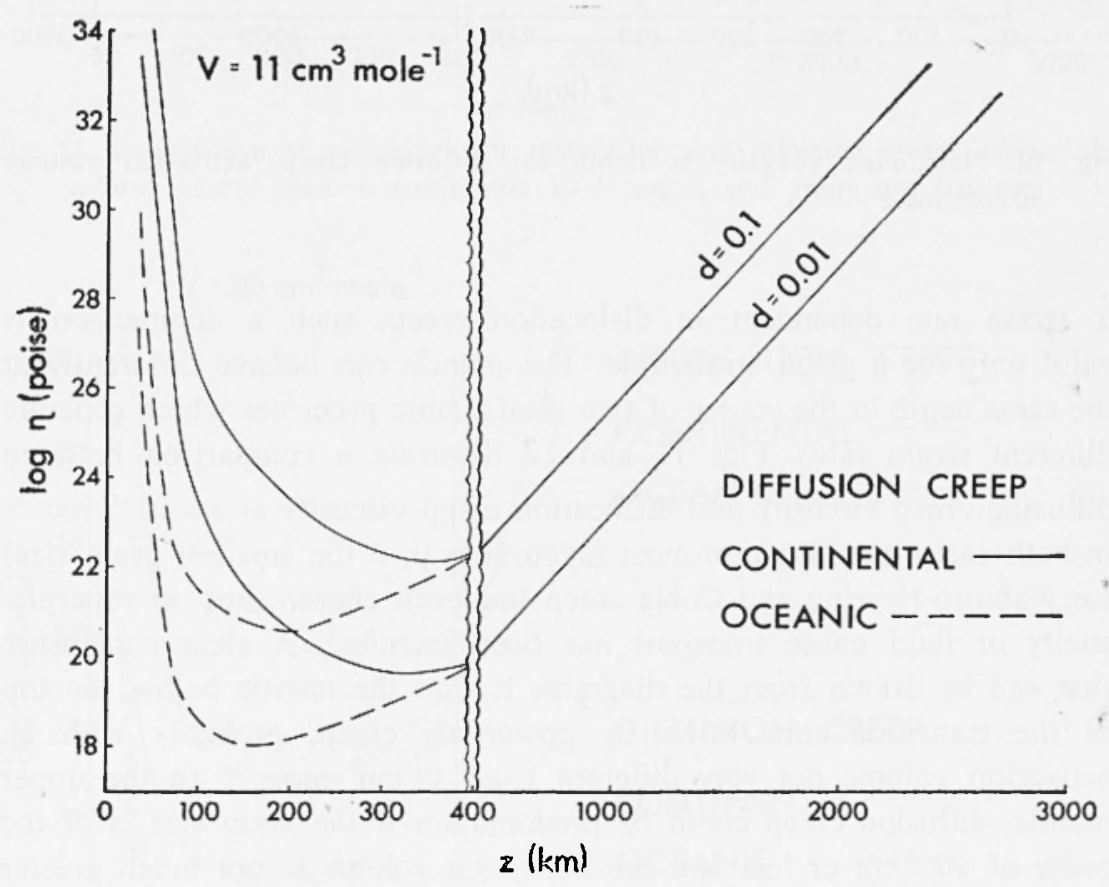

Fig. 9. Newtonian viscosity $v$. depth for diffusion creep, activation volume $11 \mathrm{~cm}^{3}$ mole ${ }^{-1}$. for grain sizes shown. 


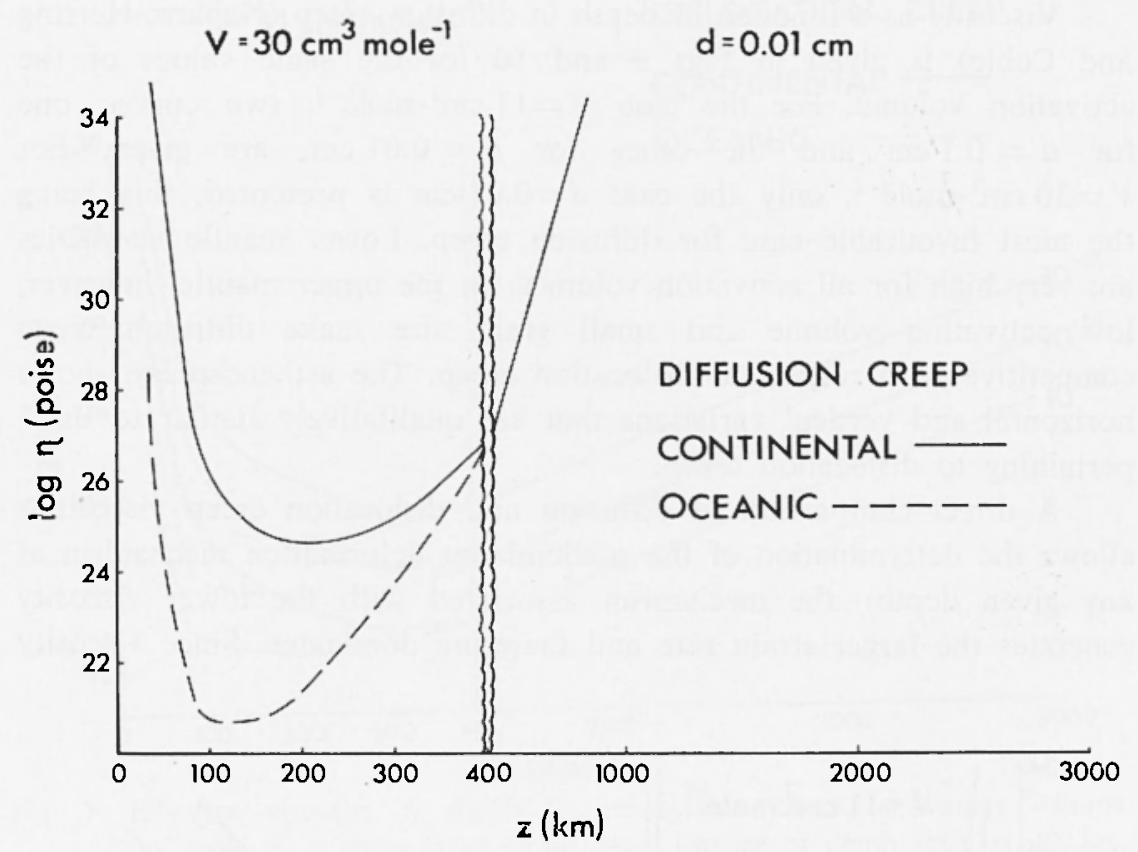

Fig. 10. Newtonian viscosity $v$. depth for diffusion creep, activation volume $30 \mathrm{~cm}^{3} \mathrm{~mole}^{-1}$.

is strain rate dependent in dislocation creep, such a comparison is valid only for a given strain rate. The mantle can behave differently at the same depth in the course of two geodynamic processes which generate diffcrent strain rates. Figs 11 and 12 illustrate a comparison between diffusion creep viscosity and dislocation creep viscosity at $\varepsilon=10^{-14} \mathrm{sec}^{-1}$ : in both cases, the situation most favourable (i. e the smallest grain size) for Nabarro-Herring and Coble creep has been chosen, but no superplasticity or fluid phase transport has been included. A clear conclusion that can be drawn from the diagrams is that the mantle below the top of the transition zone flows by power-law creep, probably with an activation volume not very different from $11 \mathrm{~cm}^{3} \cdot \mathrm{mole}^{-1}$. In the upper mantle, diffusion creep could be predominant if the grain size is of the order of $10^{-2} \mathrm{~cm}$ or less and the activation volume is not much greater than $11 \mathrm{~cm}^{3} \cdot \mathrm{mole}^{-1}$; for larger grain sizes, dislocation creep would still be predominant. Other things being equal, the suboceanic mantle has 


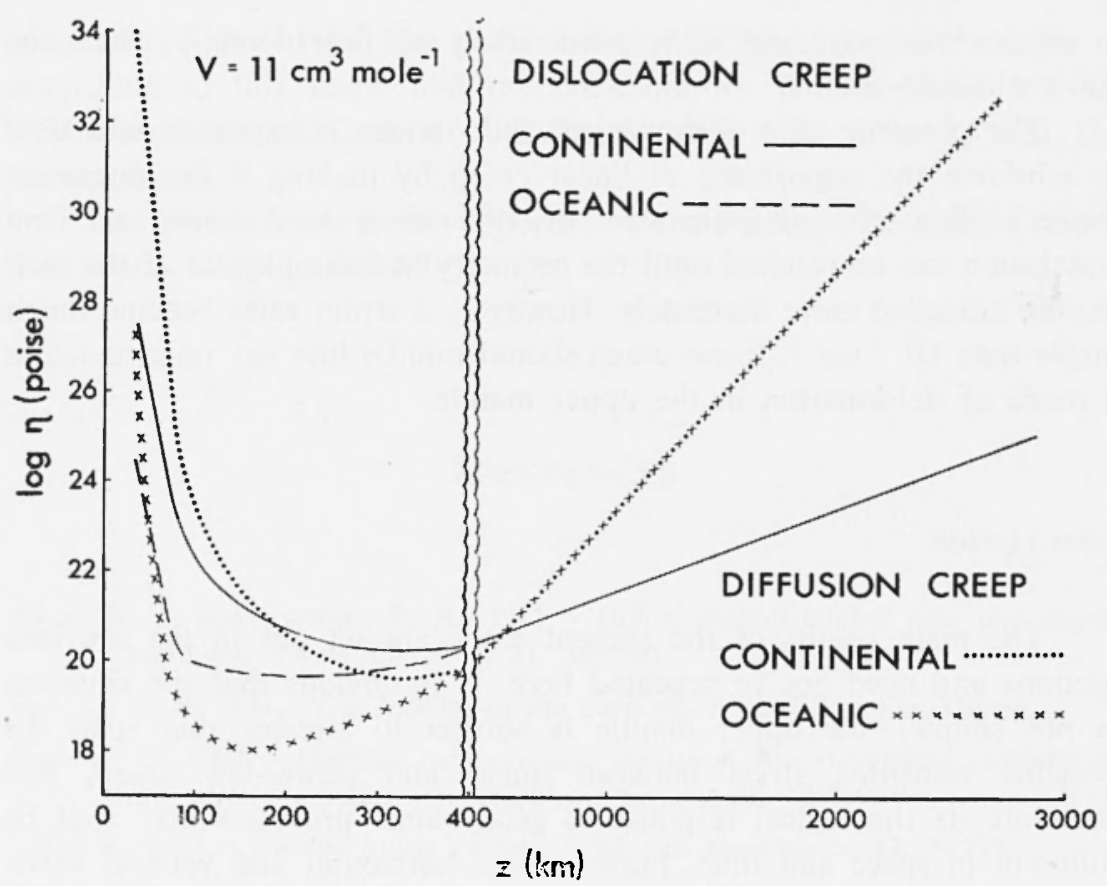

Fig. 11. Comparison of viscosities for dislocation and diffusion creep, activation volume $11 \mathrm{~cm}^{3} \mathrm{~mole}^{-1}$, strain rate $10^{-14} \mathrm{sec}^{-1}$, and grain size $0.01 \mathrm{~cm}$.

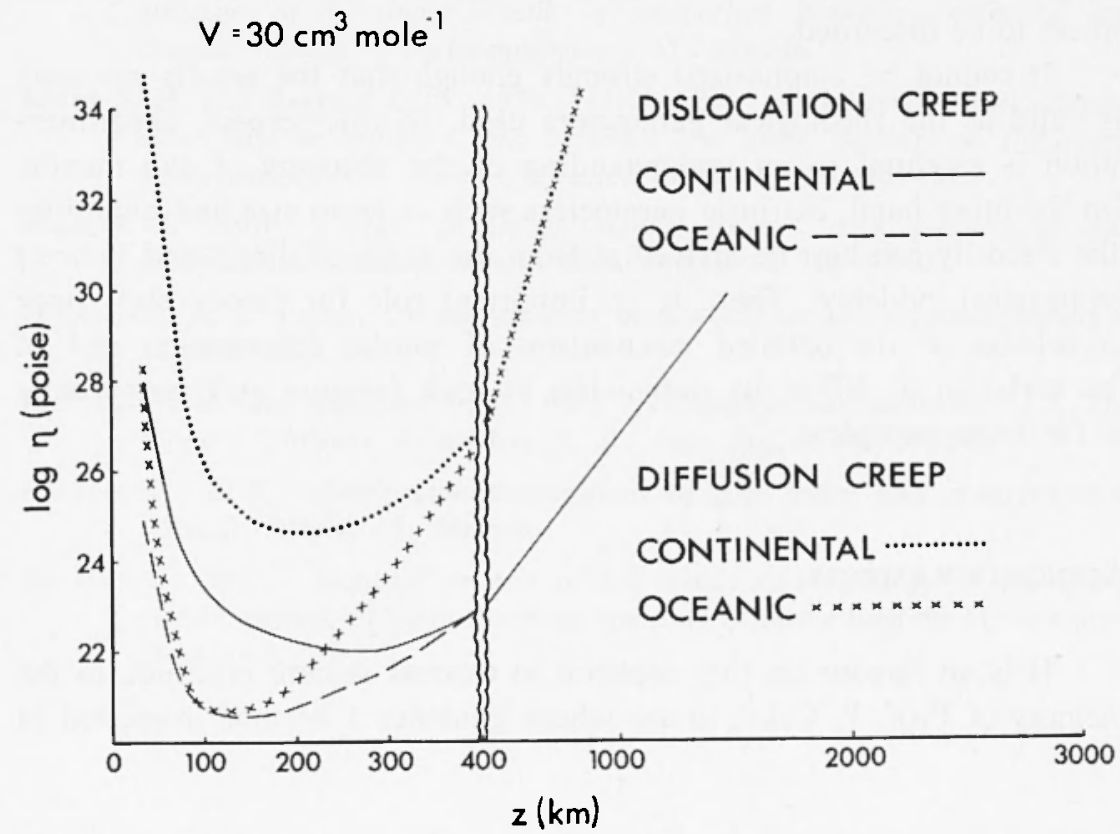

Fig. 12. Comparison of viscosities for dislocation and diffusion creep, activation volume $30 \mathrm{~cm}^{3} \mathrm{~mole}^{-1}$. 
a smaller viscosity, and it is more likely to flow lineariy, than the subcontinental mantle.

The presence of well-developed fluid phase transport would tend tc reinforce the importance of linear creep by making it the dominant mode of flow also at grain sizes of $10^{-1} \mathrm{~cm}$ or thereabouts; no firm ccnclusion can be reached until the geometry and the physics of the melt can be modelled more accurately. However, if strain rates become much larger than $10^{-14} \mathrm{sec}^{-1}$, linear creep should rapidly lose any importance as a mode of deformation in the upper mantle.

\section{Conclusion.}

The main results of the present work are set out in the previous sections and need not be repeated here. It is obvious that the situation is not simple: the upper mantle is subject to stresses that span the possible transition stress between linear and power-law creep, and therefore its rheological response to geodynamic processes may well be different in space and time. Furthermore, horizontal and vertical variaticns in grain size, melt content, anisotropy and the like will complicate its behaviour. These limitations notwithstanding, an analysis such as the one presented here allows some preliminary models to emerge and others to be discarded.

It cannot be emphasized strongly enough that the results are only as valid as the rheological parameters used. In this respect, experimentation is essential to an understanding of the rheology of the mantle. On the other hand, extrinsic parameters such as grain size and quantities like viscosity can best be arrived at from the study of direct and indirect gecphysical evidence. There is an important role for theory also, since knowledge of the detailed mechanisms of plastic deformation and of the variation of diffusivity parameters at high pressure and temperature is far from complete.

\section{ACKNOWLEDGEMENTS.}

It is an honour on this occasion to express sincere gratitude to the memory of Prof. P. Caloi, under whose guidance I became interested in 
geophysics. I should also like to thank Prof. M. Caputo for his invitation to contribute to this issue, and my collaborators W. Yzerdraat and G. Atkinson, both of Carleton University, who have helped with the computations.

This research has been supported by the National Research Council of Canada under grant A7971.

\section{REFERENCES}

Ashiby M. F. and Verrall R. A., 1973. - Diffusion-accomodated flow and superplasticity. «Acta Metall. », 21, 149-163.

Bотт M. H. P., 1971. - The Interior of the Earth. E. Arnold, London, 316 pp.

BRENNEN C., 1974. - Isostatic recovery and the strain rate dependent viscosity of the earth's mantle. «J. Geophys. Res. », 79, 3993-4401.

Calor P., 1967. - On the upper mantle. "Adv. in Geophys. ", 12, 79-211.

Carter N. L., 1976. - Steady-state flow of rocks. "Rev. Geophys. Space Phys. ", 14, 301-360.

Froidevaux C., Schubert G., and Yuen D. A., 1977. - Thermal and mechanical structure of the upper mantle: a comparison between continental and oceanic models. "Tectonophysics ", 37, 233-246.

KIRBY S. H. and RALEICH C. B., 1973. - Mechanisms of hightemperature, steadystate flow in minerals and ceramics and their bearing on the creep behaviour of the mantle. "Tectonophysics", 19, 165-194.

Nicolas A., 1976. - Flow in upper mantle rocks: some geophysical and geodynanical consequences. "Tectonophysics», 32, 93-106.

O' CONNELl R. J., 1977. - On the scale of mantle convection. "Tectonophysics», 38, $119-136$.

Peltier W. R. and Andrews J. T., 1976. - Glacial-isostatic adjustment: I. The forward problem. "Geophys. J. R. Astr. Soc. », 46, 605-646.

Ranalli G., 1974. - Geodynamic implications of rock creep and creep rupture. «Rheol. Acta », 13, 586-595.

RANALLI G., 1977. - Regional models of the steady-state rheology of the upper mantle. «Symp. on Earth Rheology and Late Cenozoic Isostatic Movements», Stockholm, 116-122. 
Stocker R. L. and Ashiry M. F., 1973. - On the rheology of the upper mantle. "Rev. Geophys. Space Phys. », 11, 391-426.

Twiss R. J., 1976. - Structural superplastic creep and linear viscosity in the earth's mantle. "Earth Planet. Sci. Letters", 33, 86-100.

Walcott R. I., 1973. - Structure of the earth from glacioisostatic rebound. «Ann. Rev. Earth Planet. Sci. », 1, 15-37.

WeERTMAN J., 1970. - The creep strength of the earth's mantle. "Rev. Geophys. Space Phys. », 8, 145-168. 